\title{
Critical State Lines of Portuguese liquefiable sands
}

\author{
Catarina Ramos $^{1,{ }^{*}}$, Cristiana Ferreira ${ }^{1}$, Fausto Molina-Gómez ${ }^{1}$ and António Viana da Fonseca ${ }^{1}$ \\ ${ }^{1}$ CONSTRUCT-GEO, Faculty of Engineering of University of Porto, Rua Dr Roberto Frias, s/n 4200-465 Porto, Portugal
}

\begin{abstract}
The Critical State framework has been used to describe the behaviour of sands and study the liquefaction susceptibility of these soils when sheared in static and cyclic conditions. The ocean coast and some fluvial basins of Portugal are characterised by the presence of sandy deposits that, combined with a moderate to high seismic activity, creates the conditions for moderate to high liquefaction susceptibility. The aim of this work is to study and compare five Portuguese liquefiable alluvial sands, collected in the centre-south of the continental territory. The experimental programme included a complete physical identification of the five materials and a series of triaxial tests in drained conditions. The specimens were prepared at a high initial void ratio (loose), using the moist-tamping technique with an appropriate initial water content, reaching void ratios close or slightly higher than $\mathrm{e}_{\max }$. The specimens were fully saturated, isotropically consolidated and statically sheared at constant strain rate until reaching the critical state. Shear wave velocities after consolidation were measured using bender elements. The critical state and small-strain stiffness parameters are discussed and compared, evidencing the differences between these soils. Relationships between some of these parameters and physical characteristics are obtained.
\end{abstract}

\section{Introduction}

Critical State Soil Mechanics is a framework that globally describes the mechanical behaviour of soils, based on effective stresses [1]. The behaviour of loose sands that contracted and dense sands that dilated to approximately the same void ratio was firstly explored by Casagrande in 1936, that introduced the term critical void ratio [2]. This parameter relates to the mean effective stress, and its value decreases as the stress increases. This relationship was reported by Taylor [3] and it represents the Critical State locus. In the 2D plane, the locus is a line, commonly known as Critical State Line (CSL). This framework is based on the occurrence of a unique state reached when the soil is subjected to a distortional load and states that the density of soils is a state variable. The soil behaviour depends on its initial state, characterized by the initial void ratio and stress state. Soils on a dense state have a peak before reaching the ultimate (also known as critical) state, while soils on a loose condition only increase until the ultimate state. As for the volumetric strains, dense soils experience a small compression and then dilate (expand), while loose soils compress as the shear stresses increase. The main characteristic of the critical states is that, during shearing, all soils will ultimately reach their critical states, which are independent from the initial states [4]. Many works show that the critical state framework can be effectively applied to describe the behaviour of different clean sands [5-7].

In the triaxial test framework, the critical state is defined by the deviatoric stress $(q)$, the mean effective stress $\left(p^{\prime}\right)$, as well as the volumetric $\left(\varepsilon_{v}\right)$ and shear $\left(\varepsilon_{s}\right)$ strains, presented in equations (1) to (4), respectively.

$$
\begin{gathered}
q=\sigma_{a}^{\prime}-\sigma_{r}^{\prime} \\
p^{\prime}=\left(\sigma_{a}^{\prime}+2 \sigma_{r}^{\prime}\right) / 3 \\
\varepsilon_{v}=\varepsilon_{\mathrm{a}}+2 \varepsilon_{\mathrm{r}} \\
\varepsilon_{s}=2 / 3\left(\varepsilon_{\mathrm{a}}-\varepsilon_{\mathrm{r}}\right)
\end{gathered}
$$

The critical state can be defined by a line in the $q-p^{\prime}$ plane, with a slope of $M$ (critical stress ratio) that is related with the critical friction angle $\left(\phi^{\prime}\right.$ cs $)$ using equation (5), for the compression case (i.e. when $\sigma_{a}^{\prime}>$ $\left.\sigma_{\mathrm{r}}^{\prime}\right)$.

$$
M=q / p^{\prime}=\left[6 \sin \left(\phi_{\mathrm{cs}}^{\prime}\right)\right] /\left[3-\sin \left(\phi_{\mathrm{cs}}^{\prime}\right)\right]
$$

In the e- $\log \left(p^{\prime}\right)$ plane, the critical state line is defined by equation (6) where $\lambda_{10}$ and $\Gamma$ are intrinsic soil properties. The gradient $\lambda$ defines the slope of the line and the parameter $\Gamma$ represents the value of the void ratio when $p^{\prime}$ equals $1.0 \mathrm{kPa}$ (in the logarithmic scale).

$$
e_{c}=\Gamma-\lambda_{10} \log \left(p^{\prime}{ }_{c}\right)
$$

Generally, the critical state line features a moderate slope at low $\mathrm{p}^{\prime}$ and then curves to a second steeper straight line at high stresses [8], often associated with particle breakage effects. It is, therefore, common to split the CSL into two lines, one for low pressures and another for higher pressures [9-11]. Instability under both cyclic and static loads is heavily influenced by compressibility. The position of the state relative to the

\footnotetext{
* Corresponding author: catarinacorreiaramos@gmail.com
} 
CSL, defines the expected behaviour associated with liquefaction susceptibility. Viana da Fonseca et al. [11] summarized these concepts and showed examples of liquefaction behaviour according to the initial state (as the one illustrated in Figure 1, from Carrera et al. [12]. According to Viana da Fonseca et al. [11], the CSL should be considered curved towards a horizontal asymptote at low stress levels and straight for high pressures. The change in gradient at high pressures is not always associated with particle breakage, as in some cases breakage was not detected [6].

As, in this work, the tests were performed with low pressures, CSL was considered as defined by equation (6).

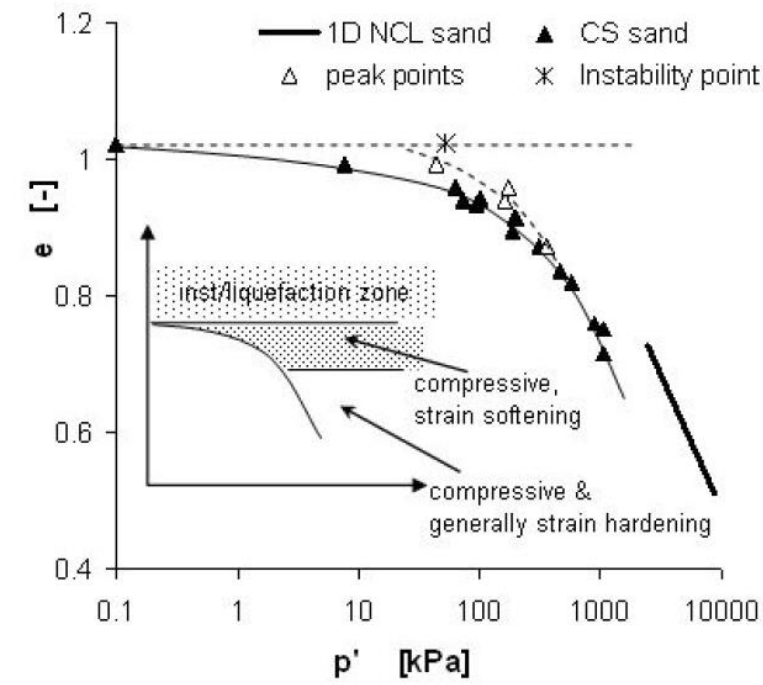

Fig. 1. Variation of liquefaction behaviour with initial state for clean sand from the Stava tailings [12]

The current work describes the critical state behaviour of five sandy soils found in Portugal, with the purpose of evaluating sands where there are historic records of cyclic liquefaction [13]. A parallel study is being performed with intact samples that confirm the contractive behaviour (defined in the stress-strain space as phase transformation line) of the sands. However, the present work focuses exclusively on the CSL with the aim of referencing risk indices associated to the state parameter. The ocean coast and some fluvial basins of Portugal are characterised by the presence of sandy deposits that, combined with a moderate to high seismic activity, create the conditions for moderate to high liquefaction susceptibility. Therefore, it is important to comprehend and fully characterise the behaviour of these soils. The identification of the Critical State Lines of soils is fundamental for the assessment of the state parameter, used nowadays to describe soil behaviour [2]. Small-strain stiffness measurements based on the shear wave velocities obtained using bender elements, are also analysed and compared with the critical state parameters. The differences are explained based on the physical characteristics of the materials and some correlations are derived.

\section{Material description}

This work focuses on the study and comparison of five different sands from Portugal. Figure 2 presents the locations where the soils were collected. The sands come from the centre-south of the continental territory, from which documented cases of liquefaction have been reported $[13,14]$.

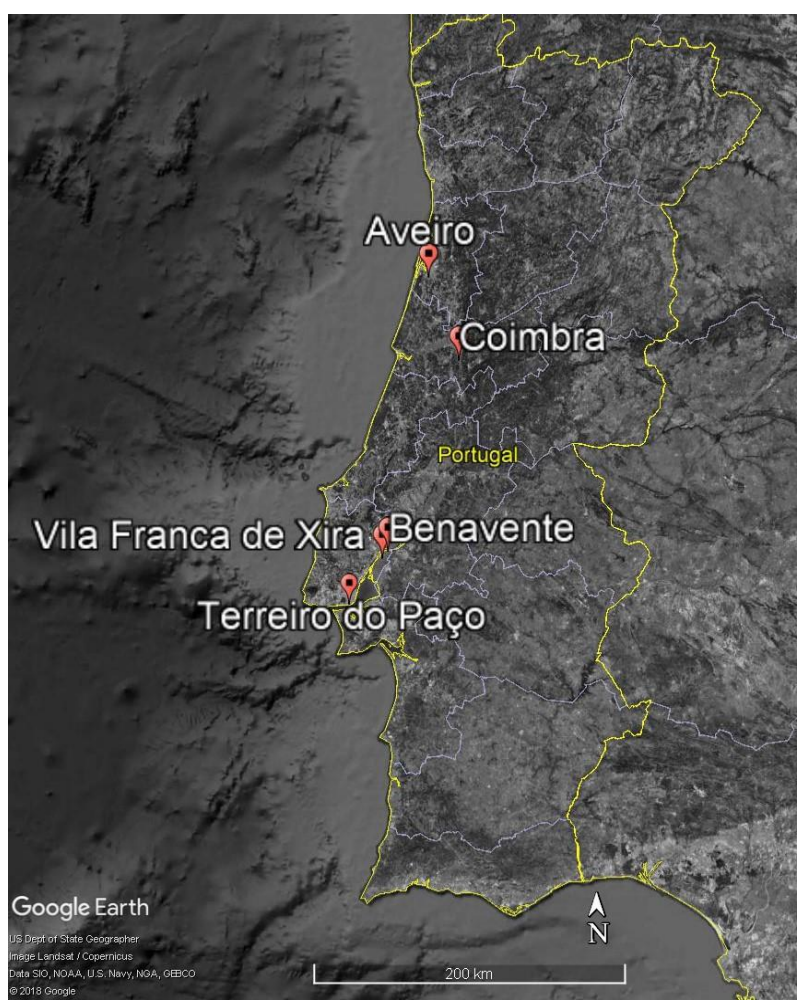

Fig. 2. Location of the sites.

Three of the materials were collected in the Lisbon region, in Benavente (NB), Vila Franca de Xira (VFX) and Terreiro do Paço (TP), and these are currently being thoroughly studied as part of two research projects on liquefaction. On the other hand, Coimbra (Co) sand has been extensively studied in the Geotechnical laboratory of FEUP (LabGEO), in previous works, namely by Soares [15]. A specific series of Round Robin tests has been carried out in different Portuguese university laboratories to evaluate the liquefaction resistance of Coimbra sand [16]. The physical characterization and test results on Coimbra sand used in this work are reported in Soares [15]. The studies on Aveiro (Av) sand were presented by Pinto [17]. These two materials have been included and described in this paper, in order to obtain an overview of Portuguese sands from different locations.

Lisbon sands are mainly composed by quartz with presence of orthoclase, albite and muscovite, which is common in this type of sand. Coimbra $(\mathrm{Co})$ and Aveiro (Av) sands also have a predominant quartz composition, based on electronic microscopy. Figure 3 shows the grain size curves of the five materials and Table 1 presents the main physical properties, namely the fines content (FC), the effective diameter $\left(\mathrm{D}_{50}\right)$, the 
coefficients of uniformity and shape $\left(\mathrm{C}_{\mathrm{U}}\right.$ and $\mathrm{C}_{\mathrm{C}}$, respectively), and the maximum and minimum void ratios $\left(\mathrm{e}_{\max }\right.$ and $\left.\mathrm{e}_{\min }\right)$.

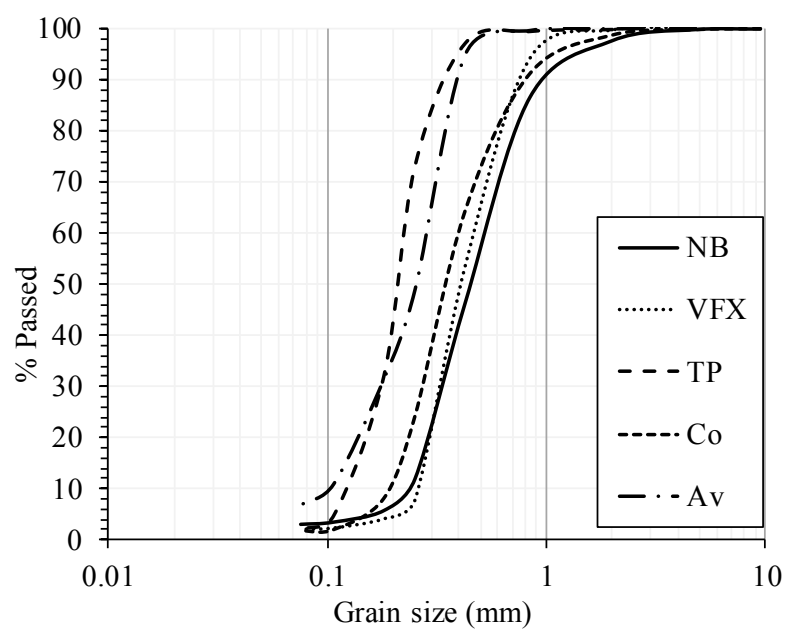

Fig. 3. Grain-size distribution curves

Table 1. Main physical properties of the soils

\begin{tabular}{|c|c|c|c|c|c|c|c|}
\hline Material & $\mathbf{F C}(\mathbf{\%})$ & $\mathbf{D}_{\mathbf{5 0}}$ & $\mathbf{C}_{\mathbf{C}}$ & $\mathbf{C}_{\mathbf{U}}$ & $\mathbf{e}_{\mathbf{m a x}}$ & $\mathbf{e}_{\mathbf{m i n}}$ & $\mathbf{G s}$ \\
\hline $\mathrm{NB}$ & 2.86 & 0.45 & 0.90 & 2.16 & 0.84 & 0.54 & 2.64 \\
\hline $\mathrm{VFX}$ & 2.10 & 0.40 & 0.89 & 1.81 & - & - & 2.64 \\
\hline $\mathrm{TP}$ & 2.21 & 0.21 & 1.13 & 1.69 & 1.01 & 0.64 & 2.66 \\
\hline $\mathrm{Co}$ & $<1.80$ & 0.36 & 1.37 & 2.13 & 0.81 & 0.48 & 2.66 \\
\hline $\mathrm{Av}$ & 6.76 & 0.26 & 1.03 & 2.80 & 0.88 & 0.53 & 2.69 \\
\hline
\end{tabular}

All sands are characterized as clean sands, with less than $8 \%$ fines content. According to the ASTM D-2487-17 classification, all are poorly graded sands (SP), with low values of $\mathrm{C}_{\mathrm{U}}$ and $\mathrm{C}_{\mathrm{C}}$, which are indicative of uniform particle size. This is also perceptible in the grain-size distribution curves in Figure 3, where very steep curves framed mostly between 1.0 and $0.1 \mathrm{~mm}$ can be observed. In addition, it can be seen that the GSD curves of all the materials exhibit similar shape. The values of specific gravity vary between 2.641 and 2.690 , which is expected for sands mainly composed by quartz. Based on macro photographs taken on the sands and using the methodology presented by Cho et al. [18], the sphericity $(\mathrm{S})$, roundness $(\mathrm{R})$ and regularity $(\rho=(\mathrm{S}+\mathrm{R}) / 2)$ of the sand particles from the different soils were estimated (Table 2). The procedure involved careful observation of individual grains and the results correspond to the average values of the analysis of 30 particles from each material. As shown in Table 2, TP sand has the lowest values of both sphericity and roundness, thus being the most angular of the five sands. NB, VFX and Av have similar values and $\mathrm{Co}$ is the material with more spherical and round particles. These conclusions are better expressed by the regularity, as provided in the table below.
Table 2. Particle shape parameters

\begin{tabular}{|c|c|c|c|}
\hline Material & Sphericity & Roundness & Regularity \\
\hline NB & 0.72 & 0.57 & 0.65 \\
\hline VFX & 0.82 & 0.49 & 0.66 \\
\hline TP & 0.56 & 0.41 & 0.49 \\
\hline Co & 0.78 & 0.63 & 0.71 \\
\hline Av & 0.70 & 0.57 & 0.64 \\
\hline
\end{tabular}

\section{Experimental program}

The experimental program comprised a series of triaxial tests in reconstituted specimens of the five sands. The tests were performed in traditional triaxial chambers, assembled with a load cell inside the pressure chamber, a linear variable displacement transformer (LVDT) outside the chamber to measure axial deformations and connected to a volume gauge to measure the volumetric variations of the sample. The cell and back pressures were measured using pressure transducers. The triaxial chambers are equipped with piezoelectric transducers (bender elements), installed on the base and top caps, for measurement of both compression $\left(\mathrm{V}_{\mathrm{P}}\right)$ and shear $\left(\mathrm{V}_{\mathrm{S}}\right)$ seismic wave velocities.

The test procedures were similar in all tests. The sample preparation involved the moist-tamping compaction of the specimens, at a certain water content (about 5\%) to facilitate the manual compaction to the desired initial void ratio. The specimens were moulded to about $140 \mathrm{~mm}$ of height and $70 \mathrm{~mm}$ of diameter, with initial void ratios between 1.00 and 0.81 for NB, VFX, $\mathrm{TP}$ and between 0.79 and 0.60 for $\mathrm{Co}$ and $\mathrm{Av}$, in an attempt to produce loose specimens. The percolation involved two phases: $\left(\right.$ i) percolation with $\mathrm{CO}_{2}$, and (ii) percolation with de-aired water. The saturation was performed increasing both the back pressure and the cell pressure, at a constant effective stress of $10 \mathrm{kPa}$, until $300 \mathrm{kPa}$ of back pressure. To check the specimen's saturation, both Skempton's B-value and the compression wave velocity were measured. The specimens were considered saturated for values of $\mathrm{B}$ higher than 0.98 and values of $V_{P}$ higher than $1500 \mathrm{~m} / \mathrm{s}$. The specimens were isotropically consolidated to the required state, and the tests were carried out at different confining pressures to obtain different points in the critical state line. The consolidation was accomplished for pressures between $20 \mathrm{kPa}$ and $1000 \mathrm{kPa}$ and the volume change was measured by means of a volume gauge. In some cases, the consolidation phase was performed in stages to allow for the measurement of shear wave velocities at different isotropic confinements. The shearing phase was performed under drained conditions, with loading rates varying between 0.007 and $0.020 \% / \mathrm{min}$, to guarantee no excess pore water pressure during shear. In order to ensure reaching the critical state, the end of each test was defined for either axial strains above $20 \%$ or volume stabilisation.

Compression and shear wave velocities were measured at the end of saturation and consolidation 
phases. The input is a sine-wave pulse and the identification of the arrival time of the shear wave was based on the methodology described by Viana da Fonseca et al. [19] as the first direct arrival of the output wave. Four sinusoidal pulses with frequencies of 2, 4, 6 and $8 \mathrm{kHz}$ were applied to measure the shear wave velocity. Figure 4 shows a photograph of the equipment used, composed by a function generator, an oscilloscope, signal input and output amplifiers, and a computer with the software to acquire the wave signals.

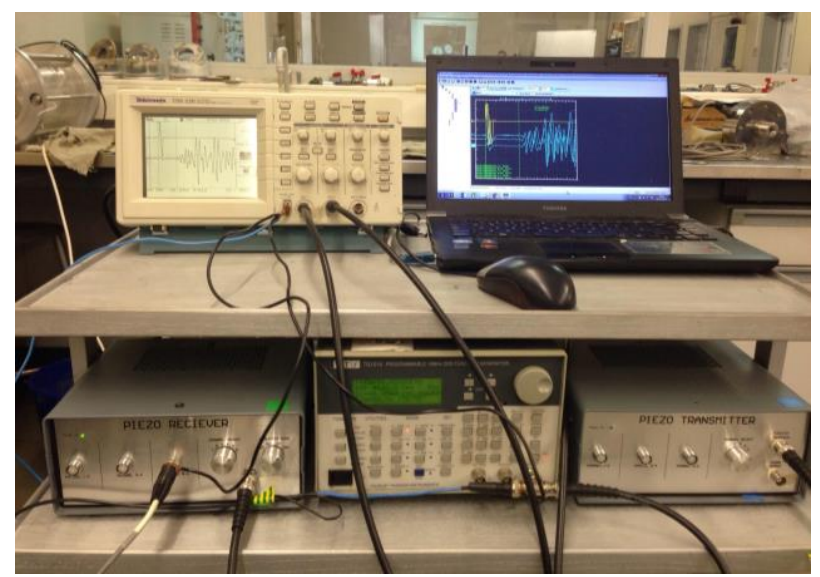

Fig. 4. Equipment used for bender element tests

\section{Results and Discussion}

\subsection{Critical State Behaviour}

Static drained triaxial tests provide valuable information about the behaviour of the soils studied. As stated above, the CS was found when the axial strains above $20 \%$ or volume stabilisation were reached. Figure 5 shows a typical stress-shear strain-volumetric strain graph, corresponding to one of the VFX tests.

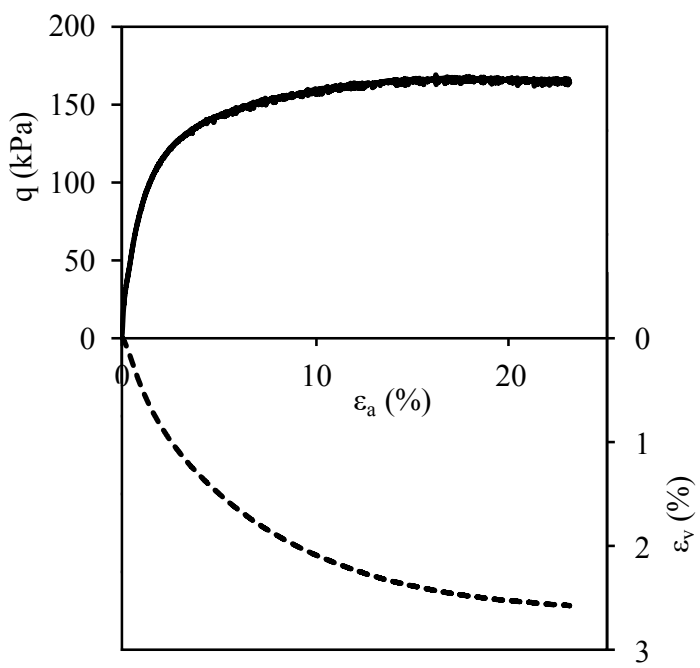

Fig. 5. Stress-shear strain-volumetric strain curves of a VFX sample

Figure 6 presents the five critical state lines, obtained from the tests performed. The lines seem almost parallel between them (except NB, which has a slightly lower slope). These trends are more clearly analysed with the critical state parameters, presented in Table 3. The gradient $\lambda$ values are around -0.060 for all sands except for $\mathrm{NB}$, which is -0.039 (lower), hence its curve is less sloped. As for the $\Gamma$ values, as these represent the position of the CSL, the lower lines correspond to lower values. Although the sands have similar physical characteristics, the position of the CSL is very distinct, meaning that the mechanical behaviour of the sands is affected by other factors: fabric, particles shape and mineralogy. The critical state lines are clearly different (Figure 6). However, when plotting the critical state points in the $q-p^{\prime}$ plane (Figure 7), these almost align, which is a consequence of the similar critical friction angle (constant volume friction angle) of all soils, despite the clear differences in the CSL in terms of state.

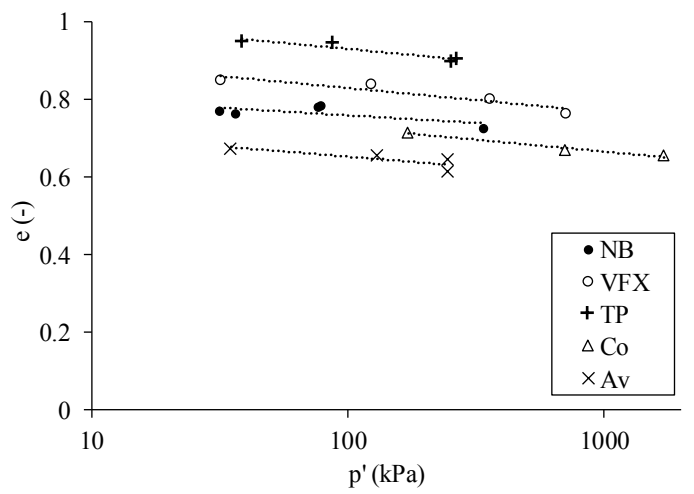

Fig. 6. Critical State lines in e-log $p^{\prime}$ plane

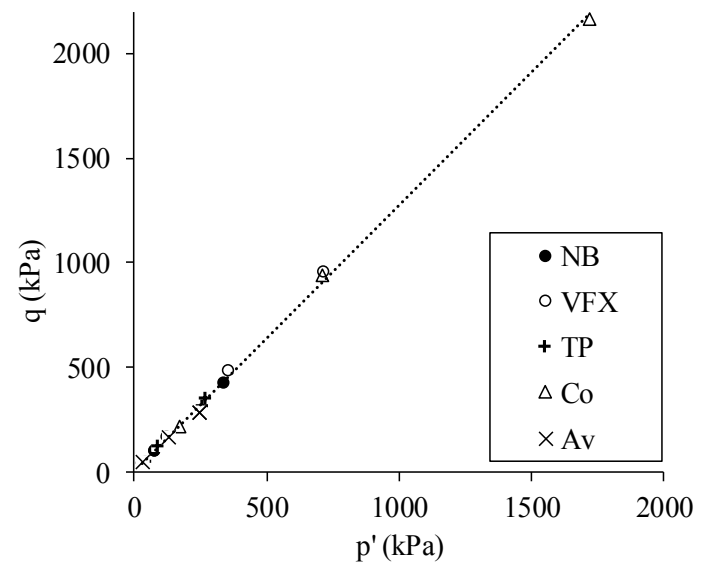

Fig. 7. Critical State points in $\mathrm{q}-\mathrm{p}^{\prime}$ plane

\section{$4.2 \mathrm{~V}_{\mathrm{s}}$ measurements}

Shear wave velocity measurements on NB, VFX and TP were taken during the current research work, while the shear wave velocity versus mean effective stress curves from Coimbra and Aveiro sands were obtained by Soares [15] and Pinto [17], respectively. Figure 8 shows the comparison between the curves obtained for $\mathrm{V}_{\mathrm{S}}$ at different confining pressures $\left(p^{\prime}\right)$ measured at the end of consolidation. 
Table 3. Critical state and shear-wave velocity parameters

\begin{tabular}{|c|c|c|c|c|c|c|}
\hline Material & $\boldsymbol{\lambda}$ & $\boldsymbol{\Gamma}$ & $\left.\boldsymbol{\phi}^{\prime}{ }_{\text {cs }} \mathbf{(}^{\mathbf{9}}\right)$ & $\boldsymbol{\alpha}(\mathbf{m} / \mathbf{s})$ & $\boldsymbol{\beta}$ & $\mathbf{r}^{\mathbf{2}}$ \\
\hline NB & -0.039 & 0.84 & 30.7 & 48.694 & 0.2671 & 0.990 \\
\hline VFX & -0.062 & 0.95 & 33.0 & 35.998 & 0.2930 & 0.998 \\
\hline TP & -0.055 & 1.04 & 33.0 & 50.869 & 0.2903 & 0.999 \\
\hline Co & -0.062 & 0.85 & 31.4 & 60.258 & 0.2731 & 1.0 \\
\hline Av & -0.053 & 0.76 & 29.3 & 45.993 & 0.3257 & 1.0 \\
\hline
\end{tabular}

The stress-dependent shear wave velocity is normally computed by equation 7, where $\alpha$ is the shear wave velocity when $p^{\prime}=1 \mathrm{kPa}$ and $\beta$ is a parameter that accounts for the sensitivity of $\mathrm{V}_{\mathrm{S}}$ with respect to $p^{\prime}$ [18]. Table 3 presents these parameters for the curves represented in Figure 8.

$$
V_{S}=\alpha \cdot p^{\beta}
$$

Santamarina et al. [20] proposed a relationship between $\beta$ and $\alpha$, based on tests in a wide range of soils, $\beta=0.36-$ $\alpha / 700$. The parameters of the materials studied fit quite well with this equation (Fig. 9).

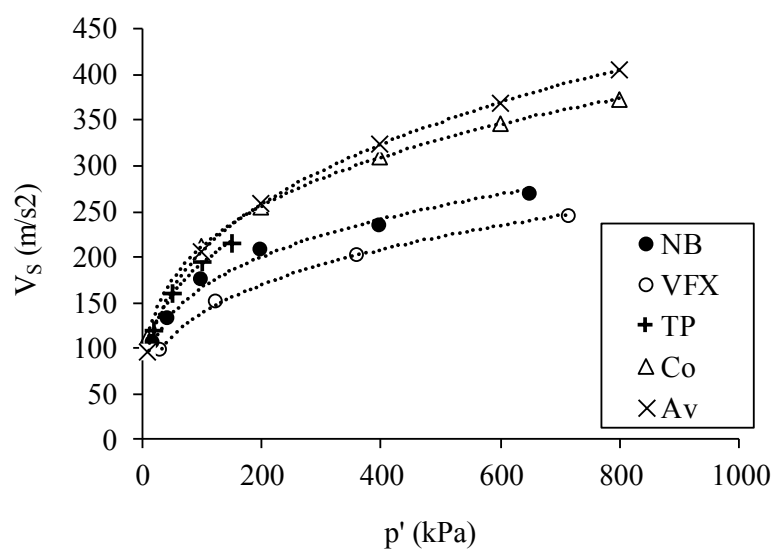

Fig. 8. Shear wave velocity versus mean effective stress curves

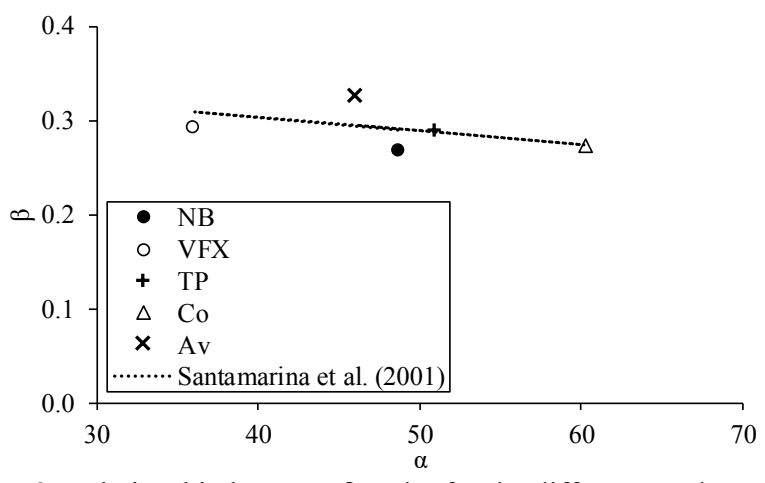

Fig. 9. Relationship between $\beta$ and $\alpha$ for the different sands

\subsection{Analysis and Discussion}

The critical state parameters were compared with physical characteristics of the five sands and some correlations were obtained. Figures 10 and 11 show the relationships between the uniformity coefficient $\left(\mathrm{C}_{\mathrm{U}}\right)$ and two critical state parameters ( $\Gamma$ and $\phi^{\prime}{ }_{\mathrm{cs}}$ ). It is interesting to notice that the parameters for the reference material Hostun RF (0\%), described in Cho et al. [18], also fit well with the observed trends for the tested sands. The R-squared value is high in both cases, which is indicative of good correlations.

The materials with lower shape coefficient $\left(\mathrm{C}_{\mathrm{C}}\right)$ and higher $\mathrm{D}_{50}$ (NB and VFX) have lower Vs- $p^{\prime}$ curves and higher CSL. These relations evidence that the shape of the particles can influence soil behaviour in both critical state and small-strain stiffness. The different observed behaviours might be caused by differences in fabric, mineralogy or shape of the particles.

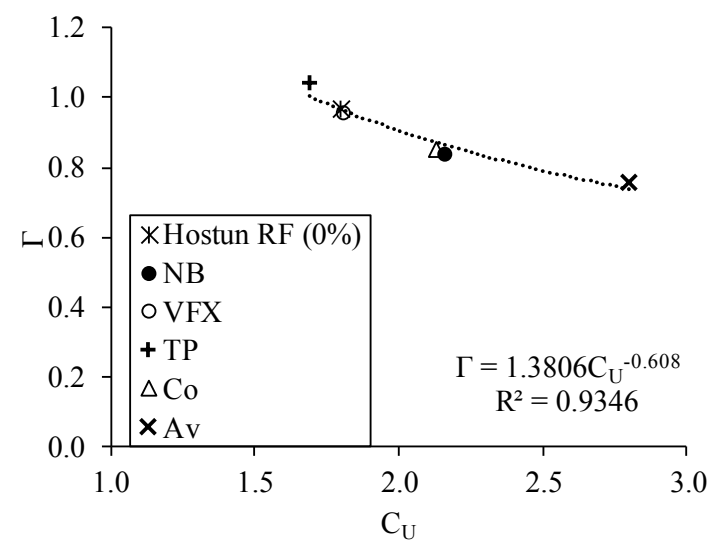

Fig. 10. Relationship between $\mathrm{C}_{U}$ and $\Gamma$

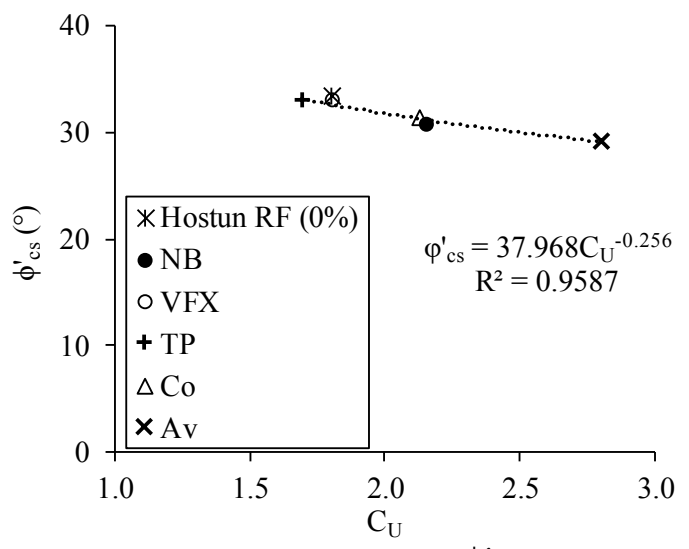

Fig. 11. Relationship between $\mathrm{C}_{U}$ and $\phi^{\prime} \mathrm{cs}$

Comparing the CSL and the $\mathrm{V}_{\mathrm{S}}-p^{\prime}$ curves, it is interesting to note that the soil with lower CSL corresponds to higher shear-wave velocities, except for the TP curve. TP sand shows a more distinct behaviour, possibly due to differences in mineralogy, fabric and especially in its more angular shape. The stiffness of sands is controlled by the confining stress, void ratio, stress history, and geological age, which govern the soil behaviour when 
sheared, hence the relation between the CSL (large strain level) and Vs (small strain level). Schnaid et al. [21] also presents evidence on how the small-strain shear modulus and shear strength are coupled in the critical state framework.

Analysing the shape parameters in Table 2, the low values of sphericity and roundness of TP sand might justify the position of the CSL. According to Cho et al. [18], a decrease in particle regularity leads to an increase in the $\Gamma$ parameter, causing the CSL to be higher, and an increase in the critical friction angle. In contrast, the influence of the shape parameters on small-strain stiffness $(\alpha)$ and sensitivity to the stress state $(\beta)$ is not so evident, as no clear trend is perceptible. However, its influence is notable in the maximum and minimum densities as the materials with lower sphericity and roundness have higher maximum and minimum void ratios.

\section{Conclusions}

This work compared the characteristics of five sands collected in Portugal, emphasising on soil grading, mineralogy and particle shape and its influence on soil behaviour. For this purpose, a significant number of static triaxial tests were performed and the critical state behaviour and the stress-dependent shear wave velocities were analysed. From this work, the following main conclusions can be drawn:

- The studied sands have similar physical properties and all can be classified as poorly-graded sands with low fines content;

- The critical state lines exhibit similar slope and are almost parallel except for the NB sand;

- Although having clearly different positions in the e- $\log p^{\prime}$ plane, the critical state points align in the $q-p^{\prime}$ plane, as all sands have similar critical friction angle;

- An upper position of the CSL translated into lower shear wave velocities, for all sands except TP, which can be explained by the differences in the shape parameters;

- The shape parameters, especially roundness, clearly influence the critical state behaviour parameters, since it was observed that $\Gamma$ and $\phi_{c s}^{\prime}$ decrease as $\mathrm{R}$ increases.

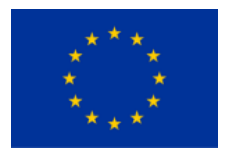

LIQUEFACT project ("Assessment and mitigation of liquefaction potential across Europe: a holistic approach to protect structures / infrastructures for improved resilience to earthquake-induced liquefaction disasters") has received funding from the European Union's Horizon 2020 research and innovation programme under grant agreement No GAP-700748. The authors would also like to acknowledge the Portuguese Foundation for Science and Technology (FCT) through the PTDC/ECM-GEO/1780/2014 (LIQ2PROEARTH) research project and the FCT Grants SFRH/BD/120035/2016 and SFRH/BPD/120470/2016, which supported this work at FEUP.

\section{References}

1. A. Schofield, C.P. Wroth, Critical State Soil Mechanics (1968)

2. M. Jefferies, K. Been, Soil liquefaction: A critical state approach (2016)

3. D.W. Taylor, Fundamentals of soil mechanics (1948)

4. J.H. Atkinson, An introduction to the mechanics of soils and foundations through critical state soil mechanics (1993)

5. K. Been, M.G. Jefferies, Géotechnique, 35, 2, 99112 (1985)

6. M.R. Coop, I.K. Lee, C.P. Wroth Memorial Symposium, Predictive Soil Mechanics, 186-198 (1993)

7. G.R. McDowell, M.D. Bolton, Géotechnique, 48, 5, 667-680 (1998)

8. R. Verdugo, K. Ishihara, Soils and Foundations, 36, 2, 81-91 (1996)

9. K. Been, M. Jefferies, J. Hachey, Géotechnique, 41, 3, 365-381 (1991)

10. J.M. Konrad, Géotechnique, 48, 2, 201-215 (1998)

11. A. Viana da Fonseca, M.R. Coop, M. Fahey, N. Consoli, 5th Int. Symp. On Deformation Characteristics of Geomaterials, 1, 84-119 (2011)

12. A. Carrera, M.R. Coop, R. Lancellotta, Géotehcnique, 61, 11, 935-946 (2011)

13. C. Jorge, Zonation of Liquefaction Potential. Application Attempt to the Portuguese Territory, MSc Thesis (1993)

14. A. Viana da Fonseca, C. Ferreira, C. Ramos, A.S. Saldanha, S. Amoroso, C. Rodrigues, Bulletin of Earthquake Engineering (under review)

15. M. Soares, Evaluation of soil liquefaction potential based on laboratory data. Major factors and limit boundaries, $\mathrm{PhD}$ Thesis (2014)

16. J.A. Santos, R.C. Gomes, J.C. Lourenço, F. Marques, P. Coelho, R. Azeiteiro, L.A. Santos, V. Marques, A. Viana da Fonseca, M. Soares, É. Abreu, D.M.G. Taborda, 15th World Conf. On Earthquake Eng. (2012)

17. A. Pinto, Abordagem à problemática da amostragem em solos granulares com envelhecimento natural através de ondas sismicas, MSc Thesis, in portuguese (2014)

18. G.-C. Cho, J. Dodds, J.C. Santamarina, J. Geotech. Geoenviron. Eng., 132, 5, 591-602 (2006)

19. A. Viana da Fonseca, C. Ferreira, M. Fahey, Geotech. Test. J., 32, 2, 91-107 (2009)

20. J.C. Santamarina, K.A. Klein, M.A. Fan, Soils and Waves (2001)

21. F. Schnaid, J. Bedin, A. Viana da Fonseca, L. de Moura Costa Filho, J. Geotech. Geoenviron. Eng., 139, 12, 2136-2144 (2013) 